\title{
ARIMA Based Wind Speed Modeling for Wind Farm Reliability Analysis and Cost Estimation
}

\author{
Rajeevan.A.K. ${ }^{\dagger}$, P.V Shouri* and Usha Nair**
}

\begin{abstract}
Necessity has compelled man to improve upon the art of tapping wind energy for power generation; an apt reliever of strain exerted on the non-renewable fossil fuel. The power generation in a Wind Farm (WF) depends on site and wind velocity which varies with time and season which in turn determine wind power modeling. It implies, the development of an accurate wind speed model to predict wind power fluctuations at a particular site is significant. In this paper, Box-Jenkins ARIMA (Auto Regressive Integrated Moving Average) time series model for wind speed is developed for a 99MW wind farm in the southern region of India. Because of the uncertainty in wind power developed, the economic viability and reliability of power generation is significant. Life Cycle Costing (LCC) method is used to determine the economic viability of WF generated power. Reliability models of WF are developed with the help of load curve of the utility grid and Capacity Outage Probability Table (COPT). ARIMA wind speed model is used for developing COPT. The values of annual reliability indices and variations of risk index of the WF with system peak load are calculated. Such reliability models of large WF can be used in generation system planning.
\end{abstract}

Keywords: ARIMA model, Economic analysis, Reliability model, Wind energy, Wind farms (WFs).

\section{Introduction}

Electrical power generation and its utilization is one of the key indicators of overall development of any country. Currently conventional fossil fuel based power plants supply major portion of world's energy need, which leads to green house gases and global warming. Statistics shown by International Energy Agency (IEA), indicate that in the next 25 years the global energy demands will increase by $90 \%$ from the current demand. Thermal power sources account for almost $65 \%$ of the total installed capacity in the world in the year 2014 and this share is expected to reduce gradually in near future since renewable energy sources penetrated more into existing energy market. To address the issues of global warming, world is looking forward to green energy sources, which are cleaner, abundant, environmentally friendly and inexhaustible. Among the various green energy technologies, wind energy conversion system is the most accomplished technology that can effectively minimize environmental pollution, eliminate fuel price variations and economically beneficial. Presently power generation from WFs using mega watt class wind turbines (WTs) is cheaper than any other renewable energy generation and it can race with coal based power generation at present cost. As per the World Wind Energy

$\dagger$ Corresponding Author: Division of Electrical Engineering, School of Engineering, CUSAT. Cochin, India. (rajeevanak@gmail.com)

* Dept. of Mechanical Engineering, Model Engineering College. Cochin. India. (pvshouri@gmail.com)

** Division of Electrical Engineering, School of Engineering, CUSAT Cochin, India. (ushanair4@gmail.com)

Received: November 3, 2015; Accepted: December 12, 2015
Association (WWEA) report published in February 2015, global wind energy capacity reached $370 \mathrm{GW}$ by the end of January 2015 and the global wind power contribution is close to $4 \%$ of world's electricity demand [1]. Today around 103 countries are utilizing wind energy on commercial basis. According to WWEA, by the year 2020, the world is expecting a wind capacity of more than $700 \mathrm{GW}$. Worldwide, irrespective of whether developed or developing countries, energy demand shall soar up even as the standard of living gets upgraded.

The increasing trend towards renewable forms of power generation, and in particular, wind, is facing new operational challenges. The uncertainty associated with wind is an issue which must be considered for wind power to be successfully integrated into an existing electric power system. This uncertainty can be managed through the use of suitable wind forecasting methodologies. A number of studies concerning ARMA (Auto Regressive Moving Average) wind speed modeling and reliability analysis have been reported in the literature [2-8]. It has been shown that stochastic wind speed can be approximated by an ARMA model of order (n, n-1) and describes method for fitting wind speed models [2]. In reference [4] the wind speed is modeled using ARMA method and the impact of replacing the conventional generating system with wind energy conversion system (WECS) on reliability indices are examined on RBTS and IEEE-RTS. The results show that to sustain a reliability criterion, the wind turbine generator (WTG) capacity should be higher than the conventional generating units. Also the system reliability can be improved by locating WTG units at multiple 
independent sites. In addition to this, energy storage in connection with WECS can enhance the continuity of wind energy and hence can improve the reliability contribution $[3,7]$. Wind speed simulation using ARMA model generates both positive and negative values and the entire negative values are set to zero during reliability analysis [5]. This in turn may result in some error in further calculations, resulting analysis and future predictions.

References $[9,10]$ present, how ARIMA technique can be used for load forecasting in power system with better accuracy. In [11] authors propose a method to predict electricity price in the electricity market of California and Spain using ARIMA technique finding good results. A comprehensive fractional ARIMA model for forecasting hourly mean wind speeds is presented in [12] and the results show that by this method the forecasting accuracy is enhanced by an amount of 42 percentages in comparison with the persistence technique. In [13], a limited ARIMA model is used for wind power modeling relying on annual wind power measurement at Nysted offshore WPP in Denmark. The LARIMA model is developed by introducing a limiter in ARIMA model to represent the lower and upper bounds of the wind power.

Box-Jenkins ARIMA modeling of wind speed, a novel technique for evaluating reliability indices of large WF is detailed in this paper. Wind speed is a nonstationary random process, but forecasting wind speed using ARMA, the same is assumed to be stationary time series. In ARIMA modeling, it is possible to convert a nonstationary time series into an associated stationary time series by taking differences, without changing basic statistical characteristics. This unique property of ARIMA provides better model accuracy. So in this paper an ARIMA model of wind speed is developed to evaluate reliability indices. The paper is organized as follows. Section 2 introduces the significance of capacity factor in WF. ARIMA model for the site is identified, simulated and an eleven state power generation model is deduced for the site in section 3 . Reliability models of WF are developed with the help of load curves of the utility grid in section 4. Economic viability of WF is checked in section 5. Results and discussion including reliability analysis and energy cost analysis are given in section 6. Finally in section 7 concluding remarks of the paper and future works are explained.

\section{Capacity Factor}

Capacity factor (CF) and average energy output over a period of time are the two key performance indicators of a WT. CF can be expressed as the ratio of average power output to the rated output power of the WT and the average power output is a more useful index than rated power. It is commonly accepted that wind speed statistical behavior can be accurately depicted by Weibull probability density function, which is given as.

$$
f(v)=\frac{k}{c}\left(\frac{v}{c}\right)^{k-1} \exp \left[-\left(\frac{v}{c}\right)^{k}\right]
$$

where $k$ and $c$ are the shape and scale parameters, which can be estimated from the statistical analysis of wind speed.

Based on Weibull distribution, the average power $p_{\text {out }}$ is given by [14]

$$
P_{\text {out }}=P_{r}\left[\frac{e^{-\left(\frac{v_{c}}{c}\right)^{k}}-e^{-\left(\frac{v_{r}}{c}\right)^{k}}}{\left(\frac{v_{r}}{c}\right)^{k}-\left(\frac{v_{c}}{c}\right)^{k}}-e^{-\left(\frac{v_{f}}{c}\right)^{k}}\right]
$$

$P_{r}$ is the rated value of electrical power of WT and its $\mathrm{CF}$ is given as

$$
C F=\frac{P_{\text {out }}}{P_{r}}
$$

Therefore

$$
C F=\frac{e^{-\left(\frac{v_{c}}{c}\right)^{k}}-e^{-\left(\frac{v_{r}}{c}\right)^{k}}}{\left(\frac{v_{r}}{c}\right)^{k}-\left(\frac{v_{c}}{c}\right)^{k}}-e^{-\left(\frac{v_{f}}{c}\right)^{k}}
$$

where $v_{c}, v_{r}, v_{f}$ are cut-in wind speed, rated wind speed and furling or cut-out wind speed respectively. The net energy output per annum $E_{0}$ is given by.

$$
E_{0}=P_{\text {out }} \times 8760(K W h)
$$

Further, CF is a function of site specifications and WT speed parameters. It is beneficial to both manufacturer and consumer for the cost effectiveness of a WECS can be approximated by the $\mathrm{CF}$ of the turbine. In general higher the value of $\mathrm{CF}$ the better is the economic performance.

\section{Methodology}

\subsection{ARIMA model}

ARIMA time series forecasting procedure has been developed by G.E.P BOX and G.M Jenkins [15]. A general $\operatorname{ARIMA}(p, d, q)$ is given by

$$
\phi_{p}(B) w_{t}=\theta_{q}(B) e_{t}
$$

where

$\phi_{p}(B)$ is an autoregressive operator of order $\mathrm{p}$ and $\theta_{q}(B)$ is a moving average operator of order $q$.

where 


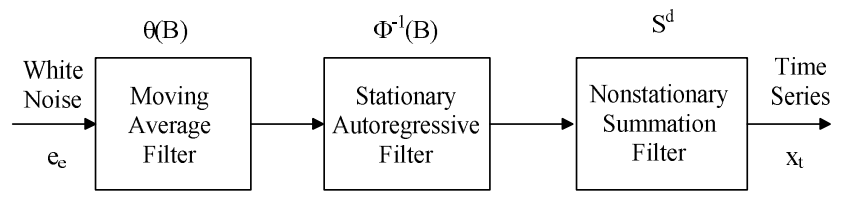

Fig. 1. A general ARIMA model represented by a series of three linear filters.

$$
w_{t}=\nabla^{d} \tilde{x}_{t}
$$

$d$ is the order of differencing and $B$ is the backward difference operator.

The general ARIMA model can be generated from white noise by means of three filtering operations as given in Fig. 1. Thus

$$
\tilde{x}_{t}=e_{t}-\beta_{1} e_{t-1}-\ldots-\beta_{q} e_{t-q}=\theta_{q}(B) e_{t}
$$

The general procedures of Box-Jenkins ARIMA involve:

- Plot the time series data and choose proper transformations. The most commonly used transformations are differencing operation and variance - stabilizing transformations.

- Calculate and examine the sample ACF (autocorrelation function) and the sample PACF (partial autocorrelation function) of the original series to further confirm a necessary degree of differencing.

- Compute and examine the sample ACF and PACF of the properly differenced series to identify the order of $\mathrm{p}$ and $\mathrm{q}$.

- Check model adequacy based on the properties of ACF and PACF of the ARIMA models.

Autocorrelations are statistical measures that indicate how a time series is related itself over time. Autocorrelation coefficients are key statistics in time series analysis; they are used to evaluate relationship among series values. The autocorrelation at lag1 represents the correlation between the original series $x_{t}$ and the same series moved forward by one period.

The autocorrelation at lag $k$ is defined by

$$
\rho_{k}=\frac{E\left[\left(x_{t}-\mu\right)\left(x_{t+k}-\mu\right)\right]}{\sqrt{E\left[\left(x_{t}-\mu\right)^{2}\right] E\left[\left(x_{t+k}-\mu\right)^{2}\right]}}
$$

where $\mu$ is the true mean of the stochastic process.

Box-Jenkins forecasting models are tentatively identified by examining the behavior of the ACF, $\hat{\rho}_{k}$ and the PACF, $\hat{\phi}_{k k}$ for the values of stationary time series $x_{b}, x_{b+1}, x_{b+2}, \ldots \ldots x_{n}$.

The autocorrelation of stationary data reduce to zero comparatively quickly, while for a nonstationary time series they are significantly apart from zero for many time lags [15].
The sample autocorrelation at lag $k$ is given by

$$
\begin{gathered}
\hat{\rho}_{k}=\frac{\sum_{i=b}^{n-k}\left(x_{i}-\bar{x}\right)\left(x_{i+k}-\bar{x}\right)}{\sum_{i=b}^{n}\left(x_{i}-\bar{x}\right)^{2}} \\
\bar{x}=\frac{\sum_{i=b}^{n}\left(x_{i}\right)}{(n-b+1)}
\end{gathered}
$$

The partial autocorrelation between $x_{t}$ and $x_{t+k}$ is given by

$$
\phi_{k k}=\frac{\operatorname{cov}\left[\left(x_{t}-\hat{x}_{t}\right)\left(x_{t+k}-\hat{x}_{t+k}\right)\right]}{\sqrt{\operatorname{var}\left(x_{t}-\hat{x}_{t}\right) \operatorname{var}\left(x_{t+k}-\hat{x}_{t+k}\right)}}
$$

Partial autocorrelations are another set of statistical measures similar to autocorrelations that are used to measure the degree of association between $x_{t}$ and $x_{t+k}$ when the effects of other time lags $1,2,3 \ldots . k$-1 are removed.

\subsection{ARIMA wind speed modeling and simulation}

The wind data for time series analysis was collected from Theni site with an installed capacity of 99MW, which was commissioned on July 2010. The measurement time interval is ten minute with a record of one year (2011). The hourly values of wind speeds are calculated by averaging six consecutive ten minute values of wind data [16]. This is depicted in Fig. 2. The sample ACF and sample PACF of

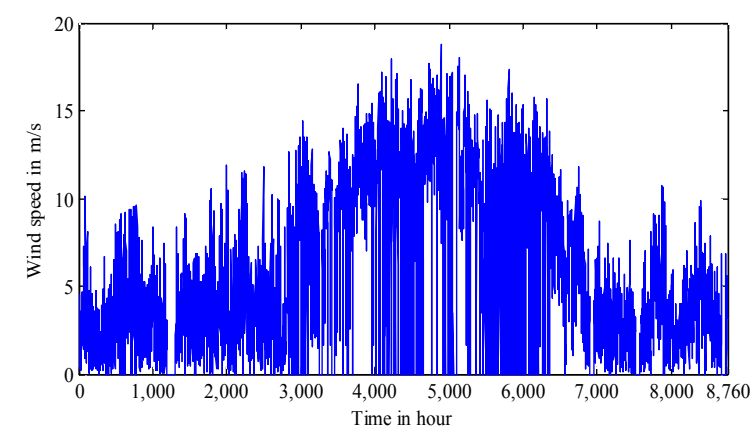

Fig. 2. Wind speed time series
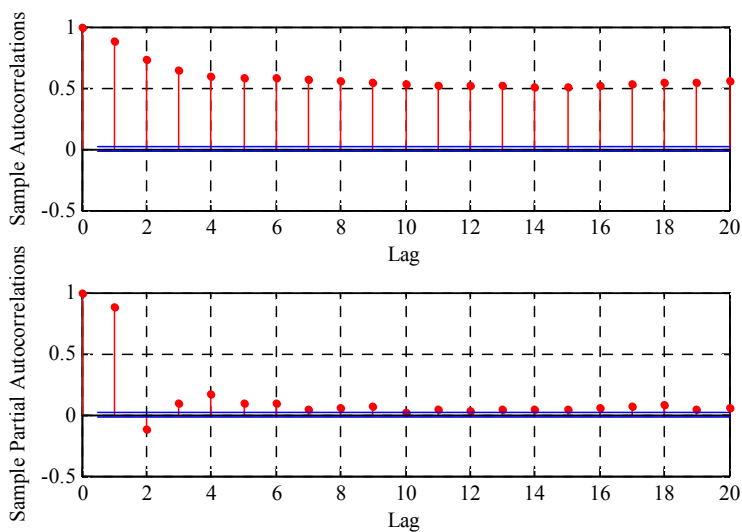

Fig. 3. ACF and PACF of observed series 
the observed time series is shown in Fig. 3 and the autocorrelation function decays very slowly. This indicates the time series is nonstationary.

A nonstationary time series is converted to stationary time series by taking first difference and the resulting time series is as shown in Fig. 4. The differencing tends to remove short and long term trends in a time series and is therefore used to achieve stationarity. Autocorrelation plot and partial autocorrelation plot of the first differenced time series is depicted in Fig. 5 and it is observed that there is no clear pattern in sample ACF and sample PACF where the time series appears to be stationary.

Using this stationary time series, a family of ARIMA models was created by varying $p$ and $q$ in the range of (0$5)$. The upper limit of value five for the model order was selected keeping frugality in mind. Out of the possible models using these variations, the optimum model was identified after adequacy check [8]. ARIMA $(1,1,2)$ model is identified as the best fitted time series model for the wind site and the model is given by

$$
y_{t}=-0.28002 y_{t-1}-0.64216 e_{t-1}-0.35784 e_{t-2}
$$

where $e_{t} \in N\left(0,2.40097^{2}\right)$, which represents a white noise whose mean is zero and variance is $2.40097^{2}$.

The simulated wind speed $s w_{t}$ at hour $t$ can be estimated as.

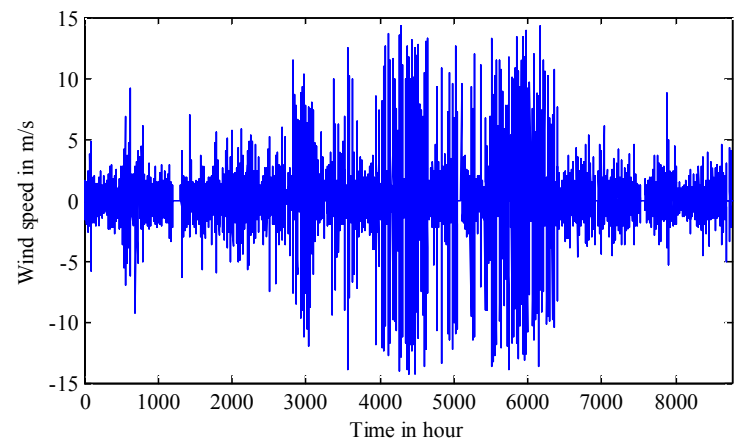

Fig. 4. First difference time series of observed wind speed

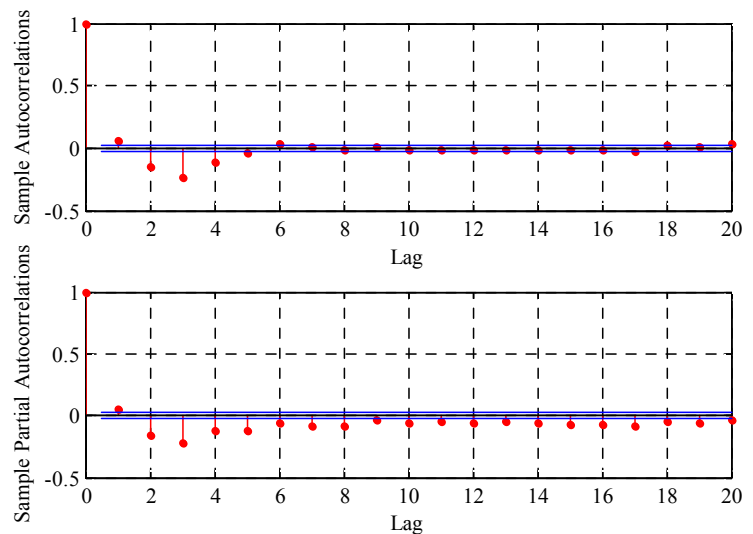

Fig. 5. Autocorrelation functions of first difference series.

$$
s w_{t}=\mu_{t}+\sigma_{t} \times y_{t}
$$

where: $\sigma_{t}$ and $\mu_{t}$ are the standard deviation and mean value of the measured wind speeds.

The purpose of model adequacy check is to examine how well the ARIMA $(1,1,2)$ model captures the observed time series. This can be done by comparing main statistical properties of simulated hourly wind data with those of measured data and is shown in Table 1.

Table 1. Observed and simulated wind speed properties

\begin{tabular}{c|c|c}
\hline Parameters & Mean value in $\mathrm{m} / \mathrm{s}$ & Standard deviation \\
\hline Observed wind speed & 5.87 & 4.7 \\
\hline Simulated wind speed & 6.3 & 4.9 \\
\hline
\end{tabular}

Fig. 6 explains the degree of matching of the measured and simulated wind speed probability distributions using the ARIMA $(1,1,2)$ model. It is observed that two curves are matching and the ARIMA $(1,1,2)$ model is the best way of representing the observed wind speed pattern.

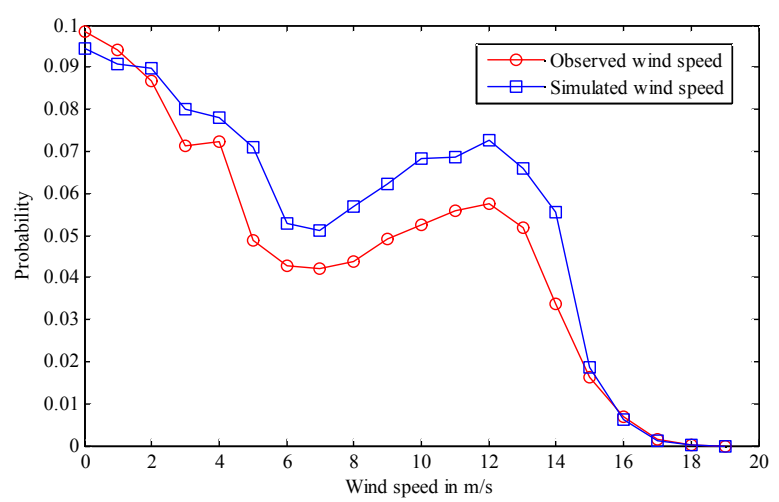

Fig. 6. Probability versus wind speed

\subsection{Wind turbine power modeling}

The WT power generation depends on three factors: wind pattern of the location, WT availability and characteristics of turbine. The WTG with rated power $\left(P_{r}\right)$ of $1.65 \mathrm{MW}$ manufactured by Vestas - V82 is used in this analysis and the details are taken from [17]. The values of operational parameters are shown in Table 2.

Table 2. Operational parameters of Vestas - V82

\begin{tabular}{c|c|c}
\hline Cut-in speed in $\mathrm{m} / \mathrm{s}$ & Rated speed in $\mathrm{m} / \mathrm{s}$ & Cut-out speed in $\mathrm{m} / \mathrm{s}$ \\
\hline 3.5 & 13 & 20 \\
\hline
\end{tabular}

The nonlinear relationship between the output power and the wind velocity of V82 - 1.65MW turbine is shown in Fig. 7. The available output power of a WTG on hourly basis at any time point $t$ can be estimated using the following nonlinear equation. 


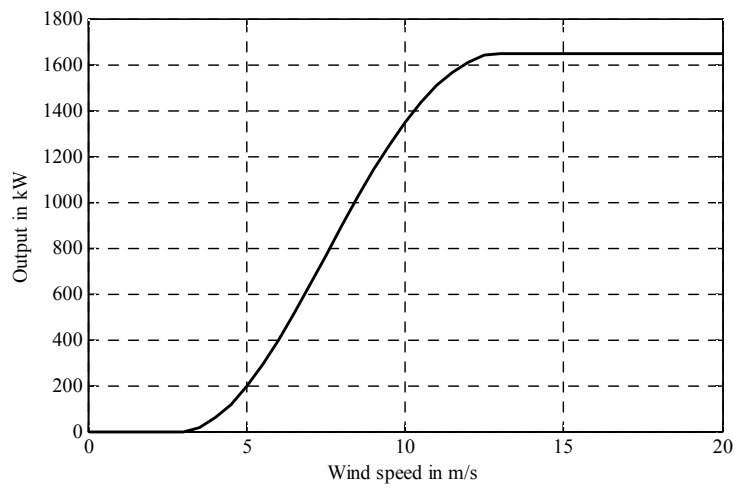

Fig. 7. Power curve of V82-1.65MW turbine

$$
\begin{aligned}
& P\left(S W_{t}\right) \\
& =\left\{\begin{array}{ll}
0 & 0 \leq S W_{t}<V_{c i} \\
\left(A+B \times S W_{t}+C \times S W_{t}^{2}\right) \times P_{r} & V_{c i} \leq S W_{t}<V_{r} \\
P_{r} & V_{r} \leq S W_{t}<V_{c o} \\
0 & S W_{t} \geq V_{c o}
\end{array}\right\}
\end{aligned}
$$

where the constants A, B and C are presented in [18].

\subsection{Capacity outage probability table}

In power system reliability assessment, conventional units are generally modeled by a two state Markov model in a failure-repair process. The conditional probability of failure / repair during a fixed interval of time is constant. This implies the failure / repair characteristics of conventional units are associated with exponential distributions [19]. The output power of a WTG varies continuously from zero to the rated power, and so it requires a multistate model. Each derated states of this model represent various energy levels. A WF generally consists of a large number of identical WTG units and they share the same wind pattern. To develop a power output model for a WF, the power generation from all the WTG units is to be added up. The power generation model required in the loss of load method is known as COPT. A COPT represents a sequence of different capacity levels and associated probabilities [19]. A number of power generation models can be created by taking different number of partial states and the accuracy of the result increases with number of states. It is observed that a five state COPT is enough in capacity adequacy assessment of wind integrated power system [6]. In this work, hourly power outputs were classified into 11 states and their corresponding probabilities were calculated.

Table 3. COPT

\begin{tabular}{c|c|c|c|c|c}
\hline $\begin{array}{c}\text { Capacity } \\
\text { out (MW) }\end{array}$ & $\begin{array}{c}\text { Capacity } \\
\text { in (MW) }\end{array}$ & Probability & $\begin{array}{c}\text { Capacity } \\
\text { out (MW) }\end{array}$ & $\begin{array}{c}\text { Capacity in } \\
\text { (MW) }\end{array}$ & Probability \\
\hline 0 & 99 & 0.30255 & 79 & 20 & 0.04218 \\
5 & 94 & 0.07679 & 84 & 15 & 0.03467 \\
21 & 78 & 0.05636 & 89 & 10 & 0.07019 \\
49 & 50 & 0.07208 & 95 & 4 & 0.05226 \\
69 & 30 & 0.04801 & 99 & 0 & 0.19361 \\
74 & 25 & 0.0513 & & & \\
\hline
\end{tabular}

Table 3 shows that probability of having full WTG output (zero percentage capacity outage) is comparatively low for this wind pattern. Since reliability indices are not much changed by the Forced Outage Rates (FOR) of WTG, it is not included in this calculation [20,21].WECS reliability is mainly affected by the wind characteristics of the site.

\section{Reliability Modeling}

As wind power sharing in conventional power system increases considerably now a days, formulation of a comprehensive reliability evaluation draws more attention. The various probabilistic concepts which are used for reliability evaluation in power system planning are LOLP (loss of load probability), LOLE (loss of load expectation) and LOEE (loss of energy expectation). The main objective in generation capacity reliability evaluation is to check whether the load demand is met by number of units generated. Load data is essential to calculate the risk evaluation. Commonly used load models are load duration curve and daily peak load variation curve. In load duration curve approach, the individual hourly load data are used. An annual load duration curve is used in this analysis. The COPT shown in Table 3 is combined with system load characteristics to give an expected risk of load loss.

LOLP is expressed as the probability that, load is more than the available power generation. This is a probabilistic index. A loss of load occurs when load is more than available generation. LOLE is the most commonly used and accepted probabilistic method in risk analysis. LOLE can be calculated as [19].

$$
L O L E=\sum_{k=1}^{N} p_{k} t_{k}
$$

where $N=$ The number of cases for which the generation outage is more than the reserve available.

$p_{k}=$ The probability of the generation outage $O_{k}$

$t_{k}=$ The period of lost load in generation outage $O_{k}$

LOEE parameter is used to access the generation system reliability. LOEE is given as [19].

$$
\text { LOEE }=\sum_{k=1}^{N} E_{k} p_{k}
$$

where $E_{k}=$ Energy curtailed by the capacity outage $O_{k}$. The total energy demand is calculated by computing the area under the load duration curve.

Installed capacity of the WF under consideration is 99MW. The hourly average power generation of the WF in year 2011 is $22 \mathrm{MW}$. This quantity is too low in comparison with installed WF capacity and this is because of the uncertainty in wind speed and the wind turbines availability 
etc. For risk analysis, knowledge of load duration curve is essential. Since WF provides power to the utility grid, it is better to apply the analysis to the load duration curve for the utility grid. To separate the contribution of WF from other sources, the load duration curve is scale down in such a manner that the maximum demand of the grid is equal to hourly average power generation of the WF [22]. Here the hourly average power generation is $22 \mathrm{MW}$ which is taken as the peak load. Thus the newly deduced load duration curve for the analysis is of similar trends as that of the utility grid load curve, but with reduced magnitude and is shown in Fig.8. Using this method reliability evaluation of WF in real world circumstance is possible.

\section{Economic Aspects of Wind Power Generation}

It is difficult to estimate the total investment accurately before the WF development actually begins. The budget plan may keep provision for contingency. It is important to find out the economic outcome after the WF begins to deliver power to the grid [23]. Though the plant begins to generate revenues, it also draws costs for maintenance and operation. The viability of a WF depends on its ability to produce wind power at a lower cost. Hence it is important to find out all expenditure involved in WF over entire life period. There are a number of factors that affect the cost of wind energy. These factors mainly depends on local conditions which include: installation cost, cost of land, amount of wind power generated, wind speed, cost of WT and its life span, incentives, tax exemptions, discount rate and electricity tariff [24, 25]. Moreover, the cost of WT accounted for almost 70 percentage of the total initial investment.

\subsection{Life cycle costing}

Cost per WT rated power, cost per WT unit rotor area and cost/unit of wind energy (cost/KWh) generated are the three methods that can be used to calculate operating cost of energy produced [24]. However, cost $/ \mathrm{KWh}$ is often taken as the main economic indicator for techno-economic analysis. The widely used method to estimate the cost/ KWh is Life Cycle Costing (LCC) which utilizes the principle of time value of money. It can be described as the ratio of levelized annual wind energy costs to the annual wind energy production of the WF [24]. By using this method the cost of wind energy per unit can be estimated as.

$$
c=\frac{c_{I}}{8760 n}\left(\frac{1}{P_{r} C_{F}}\right)\left\{1+m\left[\frac{(1+I)^{n}-1}{I(1+I)^{n}}\right]\right\}
$$

where $c_{I}$ is the initial investment, $n$-is the turbine lifetime and $I$ is the real rate of interest. $8760 P_{r} C_{F}$ is the WF annual energy output in KWh. The operation and maintenance cost $C_{\text {om }}$ can be expressed as a percentage $m$ of $c_{I}$ and is given as (19).

$$
C_{o m}=m c_{I}
$$

The primary aim of WF operation and maintenance (O\&M) is to improve the WT yield and keep production cost as minimum as possible. Compared to other power plants, the $C_{o m}$ of WF is very low, since no fuel is needed. Generally WFs are designed for a technical life time of 20 years. Maintenance costs will however increase with age, therefore economic lifetime may be shorter than technical lifetime. So proper O\&M of WTs are critical in maximizing returns from a WF investment.

\subsection{Benefit cost ratio}

$B C R$ is an economic performance indicator in LCC analysis to judge economic viability of a WF and is given as [24].

$$
B C R=\frac{\text { Present value of all benefits }}{\text { Present value of all costs }}
$$

Mathematically

$$
B C R=\frac{B_{A}\left[\frac{(1+I)^{n}-1}{I(1+I)^{n}}\right]}{C_{I}\left[1+m\left(\frac{(1+I)^{n}-1}{I(1+I)^{n}}\right)\right]}
$$

where $B_{A}$ is the acquired income annually through electricity sale. If $B C R>1$; it is concluded that WF is economically attractive.

\section{Results and Discussion}

\subsection{WF Reliability analysis}

Fig. 8 demonstrates system load pattern. The study period taken for the analysis is one year and therefore 100 percentages on $\mathrm{x}$ - axis in Fig. 8 corresponds to 8760 hours $[26,27]$. The area under the system load pattern gives the energy required in that period. The annual reliability indices of WF are obtained by comparing the peak load demand 22MW with corresponding annual load duration curve and the values are shown in Table 4 . These values provide an insight to the WF annual reliability. Even though a number of indices are used for risk analysis in WECS, the most significant index is LOLE [28]. The risk index LOLE is calculated by convolving WF multistate equivalent model with load model.

Fig. 9 demonstrates the variations in risk with system peak load and is found that risk index increase with increase in peak load. Furthermore, the percentage 


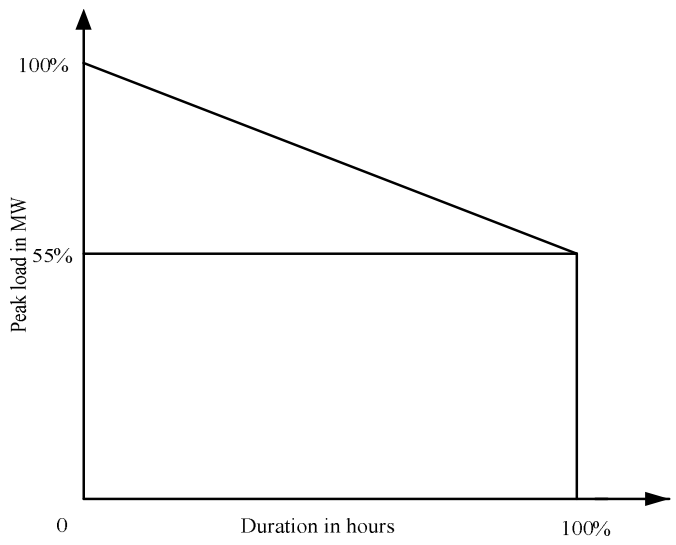

Fig. 8. System load duration curve

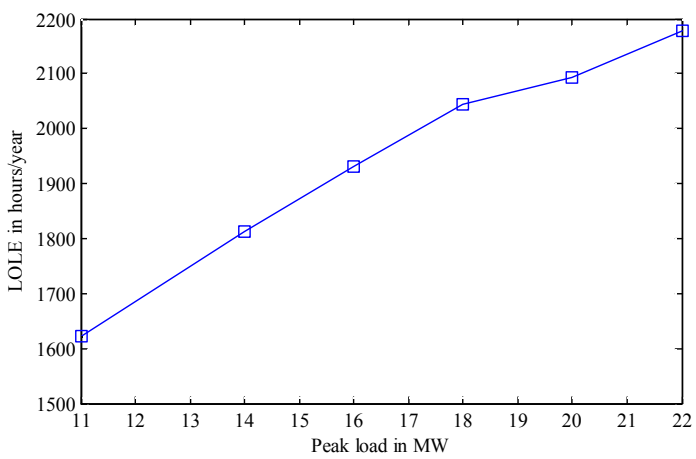

Fig. 9. LOLE versus peak load

Table 4. Annual reliability indices

\begin{tabular}{c|c|c}
\hline LOLP & LOLE in hours/year & LOEE in MWh \\
\hline 0.3491 & 2178.322 & 457.213 \\
\hline
\end{tabular}

Table 5. LOLE and reliability variations with respect to changes in peak load

\begin{tabular}{c|c|c}
\hline Peak load in MW & LOLE in hours/year & Reliability in percentage \\
\hline 22 & 2178.322 & 75.13 \\
\hline 20 & 2092.272 & 76.12 \\
\hline 18 & 2044.836 & 76.66 \\
\hline 16 & 1930.4 & 77.96 \\
\hline 14 & 1812.352 & 79.31 \\
\hline 11 & 1622.4 & 81.5 \\
\hline
\end{tabular}

reliability of WF to meet the load demand can be calculated as [22].

\section{Reliability in percentage}

$$
=\frac{\text { Number of hours }- \text { LOLE }}{\text { Number of hours }} \times 100
$$

WF reliability corresponding to different peak load values is calculated and is given in Table 5. Fig. 10 depicts the change in reliability with respect to changes in peak load. It is found from Fig. 10 that reliability improves with decrease in load demand and the change in reliability is

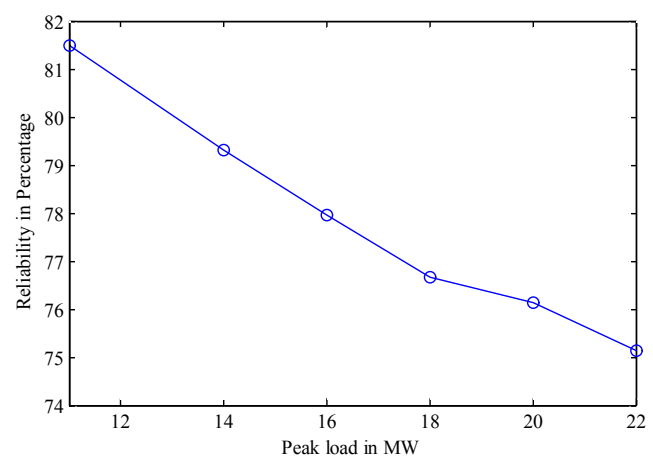

Fig. 10. Reliability versus peak load

$8.5 \%$ for $50 \%$ change in load. Thus WF provides better reliability against change in load.

\section{2 Energy cost analysis}

The economic analysis of Theni site was performed using LCC method. To determine cost/unit of wind energy, it is important to consider following assumptions [25, 29].

(i) The WT lifetime $(n)$ was considered to be 20 years.

(ii) The interest rate (i) is $8 \%$ and inflation rate (r) is $6 \%$

(iii) $C_{\text {om }}$ was considered to $1.5 \%$ of the initial investment.

(iv) It is also assumed that the WF generate equal amount of energy in each year during its useful life period.

All the above assumed values including turbine cost and other initial costs incurred for installation, land etc. are collected from the WF developer. CF is calculated using Eequation (4) with the help of cubic mean wind speed, which provides more accurate result and the value of $\mathrm{CF}$ in this site is 0.2 . It should be noted that CF of a WT at a potential site may vary from 0.15 to 0.4 . The estimated cost of wind energy/unit is Rs. 1.79 and BCR is 1.55 , which is more than one. The interest rate has great impact on economic result. The higher the interest rate, longer time it will take to pay back loan. In India interest rate that banks offer for a wind power project is around 9\% in 2008, but recently the trust in reliability of wind power has increased and hence interest rates are going down.

\section{Conclusion}

The power generated by a WECS depends on site specific wind velocity which randomly varies with time. This random variation of wind velocity is a significant factor in wind power modeling. So an accurate wind speed model to forecast wind power fluctuations at a site is important.

- This paper developed Box-Jenkins ARIMA time series model for wind speed. It is well-known that wind 
velocity does not follow a specific pattern for any particular season. This necessitates accurate modeling of wind speed like ARIMA for reliability analysis. In ARIMA modeling it is possible to convert the nonstationary wind speed time series to an associated stationary time series without changing basic statistical characteristics. Also the ARIMA model can accommodate long range correlations. These unique properties along with accuracy of the ARIMA model and its mathematical soundness provide an upper hand over conventional ARMA modeling.

- The purpose of WF generation capacity reliability estimation is to check whether the load demand is met by number of units generated. Due to the time variability of wind, WF does not provide an equivalent amount of its installed capacity consistently. While operating a grid connected WF it is worthwhile to know the magnitude of wind power and the time at which it was available to meet the load. Various probabilistic concepts which are used for generation capacity reliability estimation are LOLP, LOLE and LOEE. Since reliability indices are not much affected by FOR of WTG, it is neglected in this analysis. Here reliability evaluation of WF in real world circumstance is done by omitting the effect of other generation systems from utility grid. The values of annual reliability indices are LOLP $=0.3491$, LOLE $=2178.3220$ hours $/$ year, and LOEE $=457.2130 \mathrm{MWh}$. These indices provide an insight to the degree of matching of WF with existing load pattern in grid.

- Even though a number of indices are used for risk analysis in WECS, the most significant index is LOLE. LOLE is estimated by convolving WF multistate equivalent model with load model and the result suggests that the risk index improves with decrease in peak load.

- With the calculation of LOLE the reliability of WF to meet the load demand is estimated. The results show that reliability contribution of WF to meet the load demand is $75.13 \%$ when peak load is $22 \mathrm{MW}$ and the change in reliability is only $8.5 \%$ for a $50 \%$ change in load. It is concluded that WF provides better reliability against change in load and this result is significant in WF planning and scheduling point of view.

- LCC method is used to determine the cost of wind power generated. The estimated cost of wind energy/unit $=$ Rs. 1.79 and $\mathrm{BCR}$ of the $\mathrm{WF}=1.55$

- Since BCR of the WF is 1.55 , it can be concluded that $\mathrm{WF}$ is economical for power generation.

Accurate wind speed forecasting and possible WF output power predictions are critical factors to improve wind energy integration into grid, which in turn modify the power system reliability. In the last two decades a lot of research work has been done in this area and the accuracy of wind power prediction has improved gradually. Further research on.
- Models developed by making use of real time online wind speed data have the capability to improve short term forecasting.

- Use of recently developed artificial intelligence algorithms to improve forecasting.

- In addition to that it is important to develop new methods for wind speed forecasting in complex terrain.

\section{References}

[1] World Wind Energy Association, World Wind Energy Statistics 2015.[Online].

Available: http://www.wwindea.org

[2] Roy Billinton, Hua Chen, R. Ghajar. "Time-series models for reliability evaluation of power systems including wind energy". Microelectron Reliab; vol.36. no. 9. pp. 1253-1261, 1996.

[3] R. Billinton, Bagen, Y. Cui. "Reliability evaluation of small stand-alone wind energy conversion systems using a time series simulation model". IEE Proce. Generation,Transmission and Distribution Vol.150, Issue: 1, pp: 96-100: Jan. 2003.

[4] Roy Billinton, Guang Bai, "Generating Capacity Adequacy Associated With Wind Energy". IEEE Transactions on Energy Conversion. Vol. 19, no. 3, pp. 641- 646, Sept.2004.

[5] Rajesh Karki, Po Hu, "Wind Power Simulation Model for Reliability Evaluation". IEEE Canadian Con-ference on Electrical and Computer Engineering, pp. 541-544, May 2005.

[6] Rajesh Karki, Po Hu, Roy Billinton, "A Simplified Wind Power Generation Model for Reliability Evaluation". IEEE Transactions on Energy Conversion. Vol. 21, no. 2, pp. 533- 540, June 2006.

[7] P. Hu R. Karki R. Billinton, "Reliability evaluation of generating systems containing wind power and energy storage". IET Gener. Transm. Distrib, Vol. 3, Issue. 8, pp. 783-791.2009.

[8] R. Billinton, R. Karki, "Incorporating wind power in generating system reliability evaluation". Int J Syst Assur Eng Manag. 1(2), pp. 120-128. (Apr-June 2010).

[9] G. Gross and F. D. Galiana, "Short-Term load forecasting," Proc. IEEE, vol. 75 , no. 12, pp. 15581573, December 1987.

[10] M. T. Hagan and S. M. Behr, "The time series approach to short term load forecasting," IEEE Trans. Power Syst., vol. 2, pp. 785-791, Aug. 1987.

[11] Javier Contreras, Rosario Espínola, Francisco J. Nogales, Antonio J. Conejo, "ARIMA Models to Predict Next-Day Electricity Prices". IEEE Trans.P. Syst., vol. 18, no. 3, pp. 1014 - 1020, Aug. 2003.

[12] Rajesh G. Kavasseri, Krithika Seetharaman, "Day Ahead Wind Speed Forecasting using f-ARIMA models". Renewable Energy, vol. 34, issue 5, pp. 1388-1393. 2009. 
[13] Peiyuan Chen, Troels Pedersen, Birgitte Bak-Jensen, Zhe Chen, "ARIMA-Based Time Series Model of Stochastic Wind Power Generation”. IEEE Trans. Power Syst., vol. 25, no. 2, pp. 667-676, May.2010.

[14] G. L. Johnson, "Wind Energy Systems". Englewood Cliffs, NJ: Prentice- Hall, 1985.

[15] G. E. P. Box, G. M. Jenkins, and G. C. Reinsel, "Time Series Analysis: Forecasting and Control". 3rd ed. Englewood Cliffs, NJ: Prentice-Hall, 1994.

[16] Rajeevan. A.K, P.V. Shouri, Usha Nair. "ARIMA Modeling of Wind Speed for Wind Farm Reliability Analysis". IEEE International Conference on Magnetics, Machines and Drives (AICERA/iCMMD) pp. 1-5. July 2014.

[17] Vestas Wind Systems, [Online]. Available: http://www.vestas.com

[18] Paul Giorsetto, Kent F.Utsurogi. "Development of a new procedure for reliability modeling of wind turbine generators", IEEE Trans. Power Appar. Syst., 102, (1), pp. 134-143,1983.

[19] R Billinton and R. N. Allan, "Reliability Evaluation of Power Systems", Plenum Press, New York, 1996.

[20] Billinton R, Chowdhury AA. "Incorporation of wind energy conversion systems in conventional generating capacity adequacy assessment". IEE Proc. Gener. Transm. Distrib.139; pp. 47-56, 1992.

[21] Billinton R, Bagen. "Incorporating reliability index distributions in small isolated generating system reliability performance assessment". IEE Proc. Gener. Transm. Distrib.151; pp: 469-76, 2004.

[22] M. Carolin Mabel, R. Edwin Raj, E. Fernandez. "Analysis on reliability aspects of wind power". Renewable and Sustainable Energy Reviews.15, pp: 1210-1216, 2011.

[23] Li Wang, Tai-Her Yeh, We-Jen Lee, Zhe Chen. "Benefit Evaluation of Wind Turbine Generators in Wind Farms Using Capacity-Factor Analysis and Economic-Cost Methods." IEEE Trans. Power Syst., vol. 24, no.2, pp. 692-704, May.2009.

[24] Mathew. S. "Wind energy: fundamentals, resource analysis and economics". Heidelberg: Springer; 2006.

[25] Gökçek M, Genç MS. "Evaluation of electricity generation and energy cost of wind energy conversion systems (WECSs) in Central Turkey". Appl. Energy. 86: pp. 2731-9, 2009.

[26] M. EL-Shimy. "Adequacy-Based Placement of WECS in Egypt". IEEE International Middle-East Power System Conference, MEPCON 2008, pp. 617623. March 2008.

[27] A. A. Chowdhury, "Reliability Models for Large Wind Farms in Generation System Planning". IEEE Power Engineering Society General Meeting, Vol. 2, pp. 1926-1933, June 2005.

[28] R. L. Sullivan, "Power System Planning", McGrawHill, 1977.

[29] Adaramola M S, Paul S S, Oyedepo S O. "Asses- sment of electricity generation and energy cost of wind energy conversion systems in north-central Nigeria”. Energy Conversion and Management, 52 (12): 3363-3368, 2011.

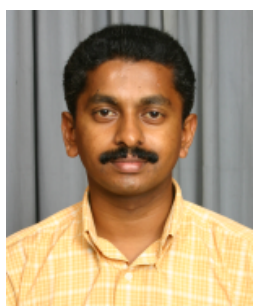

Rajeevan.A.K received B-Tech (EEE) from Mahatma Gandhi University Kottyam, Kerala and M.E. (Power Electronics and Drives) from Anna University, Chennai, India in 1995 and 2008 respectively. $\mathrm{He}$ is currently pursuing his research at Cochin University of Science and Technology, India. His area of interests includes reliability analysis, wind speed forecasting and grid integration of renewable energy.

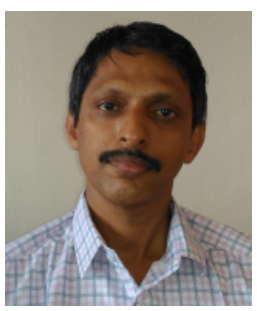

P.V. Shouri is working in Model Engineering College, Cochin as professor in Mechanical Engineering and has more than 20 years of experience in teaching. Basically a mechanical engineer, Dr. Shouri P.V is specialized in the area of energy and reliability and has made significant contributions in the specialized area.

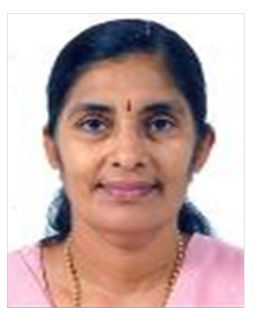

Usha Nair is a graduate and post graduate in Electrical Engineering. She completed her Ph.D in 2009 from Cochin University of Science and Technology and presently working as Associate Professor in the Department of Electrical Engineering in the same University. Her areas of interest are nonlinear dynamical analysis, control system design and time series analysis. 